DOI: $10.12737 / 19970$

УДК $630 * 432$

ТЕНДЕНЦИИ РАЗВИТИЯ ТЕХНИЧЕСКИХ СРЕДСТВ ДЛЯ ТУШЕНИЯ ЛЕСНЫХ ПОЖАРОВ Д. С. Ступников

ФГБОУ ВО «Воронежский государственный лесотехнический университет имени Г.Ф. Морозова», г. Воронеж, Российская Федерация

Проведен анализ методов и способов борьбы с лесными пожарами, по результатам которого было выявлено два метода борьбы с пожарами: непосредственное воздействие на кромку пожара (тушение), а способы, применяемые при этом, - активные способы, и методы, связанные с заведомой потерей площади при создании заградительных полос и барьеров, препятствующих распространению огня. Эти методы получили название пассивные, или косвенные. Активные способы используются при тушении низовых пожаров, а пассивные - при тушении верховых. Приведены данные, которые говорят о том, что до недавнего времени в лесном хозяйстве применялись в основном почвообрабатывающие орудия с пассивными рабочими органами для прокладки минерализованных полос, противопожарных дорог, канав и разрывов. Рассмотрена одна из перспективных инновационных разработок, направленная на решение задачи увеличения надежности за счет обеспечения защиты фрезерного рабочего органа от ударов о препятствия, повышения эффективности работы в условиях грунтов, насыщенных корнями древесно-кустарниковой растительности и уплотненных связных почв, снижения массы и габаритов, имеющая ряд преимуществ перед аналогами. Выявлены особенности конструкции и ряд преимуществ в сравнении с существующими аналогами. Проведен анализ конструкций лесопожарных машин, научно-исследовательских работ и патентный обзор, который показал, что в настоящее время остаются нерешенными задачи по профилактике и предотвращению лесных низовых пожаров. Поэтому требуется проведение дополнительных исследований, связанных с совершенствованием активных рабочих органов, созданием новых конструкций, а также оптимизацией и повышением эффективности рабочего процесса тушения и профилактики лесных пожаров.

Ключевые слова: лесной пожар, тушение, лесопожарная машина, грунт, профилактика, плуг, грунтомет, рабочий орган, фреза-метатель, отжиг, захлестывание, конструкция.

\title{
TRENDS IN THE DEVELOPMENT OF TECHNICAL MEANS FOR FIGHTING FOREST FIRES D. S. Stupnikov
}

Federal State Budget Education Institution of Higher Education «Voronezh State University of Forestry and Technologies named after G.F. Morozov», Voronezh, Russian Federation

\begin{abstract}
The analysis of methods and ways to combat forest fires, the results of which were revealed two methods of fire control: direct impact on the edge of the fire (quenching), and methods used at the same time - active methods, and methods related to the deliberate loss Square when creating boom bands and barriers to the spread of fire. These methods are called passive passive or indirect. Active methods used to extinguish fires in the grassroots, and passive - to extinguish the saddle. The data which say that until recently were used in forestry generally tools for soil with passive working bodies for laying fire lines, fire roads, ditches and tearing. Considered one of the most promising innovations aimed at solving the problem of increasing reliability by protecting the milling working body from hitting the obstacle, increase the efficiency of work in the conditions of the soil, rich roots of trees and shrubs and the compaction of cohesive soil, reducing the weight and dimensions, which has a number of advantages over similar products. The features of the design and number of advantages in comparison with existing analogues. The analysis of structural forest fire vehicles, scientific research and patent survey which showed that at present remain the task of prevention and prevention of forest surface fires. Therefore, more research is needed, related to the improvement of active working bodies, the creation of new structures, as well as optimize and improve workflow fighting and preventing forest fires.
\end{abstract}

Keywords: forest fire, suppression, the forest fire car, soil, prevention, plougher, gruntomet, working body, cutter-thrower, annealing, entanglement, construction. 
Под тушением лесного пожара понимается процесс остановки распространения огня, прекращение пламенного горения на кромке пожара и предотвращение возможности его возобновления. При этом необходимо учитывать, что горение возможно только при наличии горючего материала, окислителя и источника подогрева. Устранение или хотя бы снижение любой составной части позволяет успешно решить поставленную задачу [1].

По характеру воздействия на процесс горения различают два метода борьбы с пожарами: непосредственное воздействие на кромку пожара (тушение), а способы, применяемые при этом, - активные способы, и методы, связанные с заведомой потерей площади при создании заградительных полос и барьеров, препятствующих распространению огня. Эти методы получили название пассивные, или косвенные.

Активные способы, как правило, используются при тушении низовых пожаров, а пассивные - при тушении верховых. Пассивные способы более безопасны, обеспечивают возможность широкой механизации работ, особенно при тушении опасных пожаров [2, 3].

Существует большое число способов тушения лесных пожаров, которые обусловливаются разнообразием пожаров и условий, в которых они возникают и протекают. Все эти способы по принципу их воздействия на огонь можно разделить на четыре группы:

- захлестывание, сдувание или забрасывание грунтом кромки низового пожара;

- тушение пожара водой или растворами огнегасящих химикатов;

- прокладка минерализованных полос и канав;

- отжиг.

Два первых способа направлены на непосредственное тушение кромки пожара - это активные способы, а последующие - пассивные, т.к. они в основном предусматривают изоляцию пожара от горючего материала $[3,4]$.

До недавнего времени в лесном хозяйстве применялись в основном почвообрабатывающие орудия с пассивными рабочими органами для прокладки минерализованных полос, противопожарных дорог, канав и разрывов.

Примером таких орудий может служить плуг комбинированный лесной ПКЛ-70, который используется для обработки почвы бороздами на нераскорчёван- ных вырубках, для того чтобы можно было осуществить посадку или посев лесных культур, а также для прокладки противопожарных полос, с целью исключения распространения огня во время лесных пожаров [5].

Основное преимущество плуга ПКЛ-70 (рис. 1), в отличие от обыкновенных сельскохозяйственных, более прочная конструкция, рассчитанная на преодоление препятствий в виде пней и корней. Применяется, большей частью, не для сплошной вспашки почвы, а лишь для организации на ее поверхности отдельных борозд и минерализованных полос. Агрегатируется с тракторами ЛХТ-55, ТДТ-55А, а в более легких условиях (на песчаных и супесчаных почвах) - с тракторами ДТ-75М, МТ3-82. Ширина противопожарной минерализованной полосы - 1,2 м [5, 6].

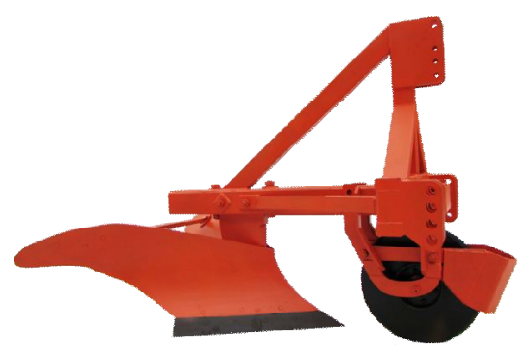

Рис. 1. Плуг ПКЛ-70

Кроме почвообрабатывающих орудий с пассивными рабочими органами применяются фрезерные машины на тракторной тяге, с помощью которых осуществляется предупреждение и тушение огня [6, 7, 9]. К ним относятся: лесные фрезы ФЛУ-0,8, ФЛШ-1,2, полосопрокладыватель ПФ-1, агрегат фрезерный АЛФ10, грунтомет ГТ-3, лесопожарный агрегат АЛП-15.

Тракторный грунтомет ГТ-3 (рис. 2) предназначен для тушения кромки лесных низовых пожаров на лесной территории с песчаными и супесчаными почвами. Агрегатируется с трактором Т-150 К. Грунтомет ГТ-3 (рис. 4) состоит из корпуса 1 , навесного устройства 2, предохранительной муфты 3, редуктора 4, карданного вала 5, рабочего органа 6, направляющего кожуха 7, гидроцилиндра 8 и опорного катка 9.

Привод рабочего органа агрегата осуществляется от ВОМ трактора через редуктор, цепную и карданную передачу. Грунт, разбрасываемый рабочим органом, может направляться как в правую, так и в левую сторону. Дальность метания регулируется за счет изменения угла установки направляющего кожуха [7, 10]. 


\section{Технологии. Машины и оборудование}

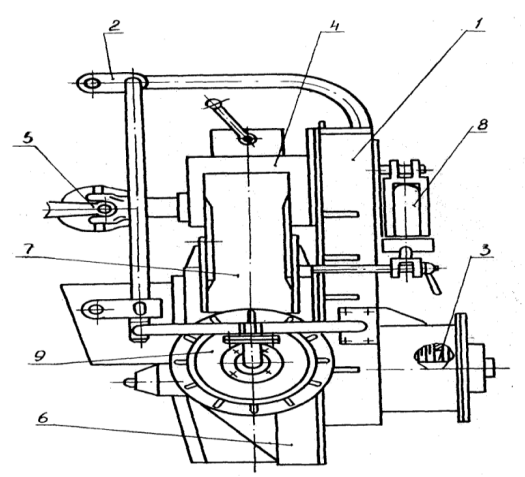

Рис. 2. Грунтомет ГТ-3

Недостатки грунтомета ГТ-3 заключаются в том, что он работает только на легких почвах (песчаных и супесчаных), на средних и тяжёлых почвах фрезы заглубляются на малую глубину и подают грунт в недостаточном количестве, чтобы обеспечить эффективное тушение пожара. Кроме того, они разработаны применительно к условиям перемещения по внугренним лесным дорогам и просекам, что препятствует применению их внугри кварталов, где масса корней, валежника и нередко пней, мешающих приблизиться и своевременно погасить кромку огня, исключая дальнейшее передвижение пожара. К тому же грунтомет ГТ-3 не может проводить многократное подновление минерализованных полос в связи с образованием глубокой борозды на легких почвах $[7,12,13]$.

Лесопожарный фрезерный агрегат АЛФ-10 (рис. 3) предназначен для прокладки заградительных минерализованных противопожарных полос в светлохвойных лесах, произрастающих на высохших песчаных почвах. Практика показала, что агрегат можно применять в брусничных и даже черничных типах леса. Рабочим органом агрегата является почвенная фреза, которая навешивается на трактор МТЗ-82 или ДТ75. Система защиты рабочего органа позволяет преодолевать без поломок ножей полнотелые (свыше 6 см) корни и камни. В зависимости от положения кожуха агрегат может осуществлять верхний выброс грунта на расстояние 10-13 м, нижний выброс на расстояние 8-9 м и обратный выброс, когда вся масса грунта распределяется равномерно по полосе шириной 1,5-2,0 м. После одного прохода агрегата создается минерализованная борозда глубиной до 20 см и шириной $70 \mathrm{cm.} \mathrm{В}$ зависимости от характера грунта и условий передвижения агрегата его рабочая скорость колеблется от 1,3 до 3,2 км/ч $[6,7,14]$

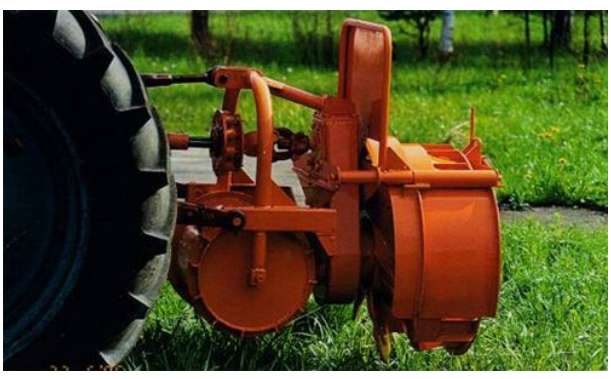

Рис. 3. Лесопожарный агрегат фрезерный АЛФ-10

Недостатками АЛФ-10 являются недостаточная дальность выброса грунта, что не позволяет использовать его в непосредственной близи кромки лесного низового пожара. Ширина прокладываемой минерализованной полосы составляет от 1,5 до 2 метров и далеко не всегда является эффективной.

В 2014 году был разработан пожарный грунтомет-полосопрокладыватель (рис. 4), предназначенный для тушения низовых пожаров, а также для прокладки защитных минерализованных полос. Эта машина имеет комбинированные рабочие органы, представленные в виде фрезы-метателя и механизма образования вала из разрыхленного почвогрунта, установленного на раме впереди фрезы-метателя. Механизм образования вала из разрыхленного почвогрунта выполнен в виде двух сферических дисков для вырезания почвенных пластов и сдвигания их к центру прохода агрегата. Это позволяет эффективно проводить работы в условиях грунтов, насыщенных корнями древеснокустарниковой растительности и уплотненных связных почв, а также выполнять функцию полосопрокладывателя $[8,5,11]$.

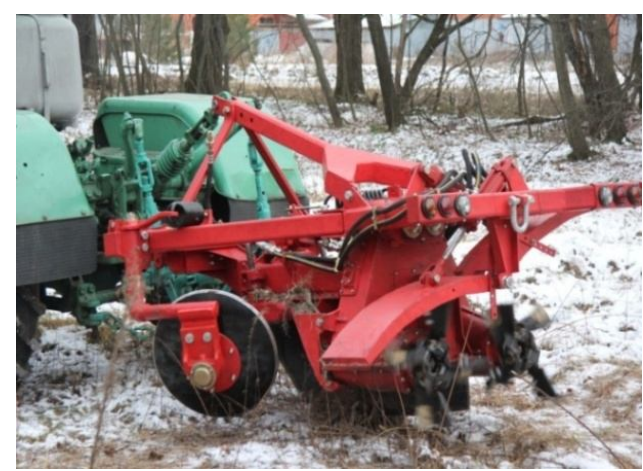

Рис. 4. Пожарный грунтомет-полосопрокладыватель

Недостатком пожарного грунтометаполосопрокладывателя является недостаточная его эффективность, обусловленная тем, что редуктор, рас- 
положенный перед фрезой-метателем, ограничивает к ней доступ грунта и, тем самым, снижает производительность машины в целом. Помимо этого фрезаметатель не защищена снизу от ударов о препятствия в виде пней и корней, что снижает надежность. Также недостатками являются большие габариты и масса, обусловленные последовательным расположением фрезы-метателя и сферических дисков.

Проведенный анализ конструкций лесопожарных машин, научно-исследовательских работ и патентный обзор показали, что в настоящее время остаются нерешенными задачи по профилактике и предотвращению лесных низовых пожаров. Лесные плуги и канавокопатели создают узкую минерализованную полосу (1-2 м), которая не всегда эффективна, а фрезерные полосопрокладыватели и грунтометы энергоемки и малопроизводительны, т. к. фрезеруют задернелую почву и агрегатируются с тракторами с ходоуменьшителем. Поэтому требуется проведение дополнительных исследований, связанных с совершенствованием активных рабочих органов, созданием новых конструкций, а также оптимизацией и повышением эффективности рабочего процесса тушения и профилактики лесных пожаров.

Одной из перспективных инновационных разработок, направленных на решение задачи увеличения надежности, за счет обеспечения защиты фрезерного рабочего органа от ударов о препятствия, повышения эффективности работы в условиях грунтов, насыщенных корнями древесно-кустарниковой растительности и уплотненных связных почв, снижения массы и габаритов, является лесопожарная грунтометательная машина (рис. 5).

Она состоит из гидравлического мотора 1 , кожуха-рыхлителя 2 с двумя окнами, рамы с навесным механизмом 3, фрезерных рабочих органов 4, ножей 5, пластин, направляющих грунт, 6.

Лесопожарная грунтометательная машина работает следующим образом. Когда трактор с закрепленной на задней навеске лесопожарной грунтометательной машиной начинает движение, гидравлический мотор 1 вращает фрезерный рабочий орган 4, кожухрыхлитель 2 вместе с ножами 5 заглубляется в грунт, рыхлит его и разрезает мелкие корни. Затем разрыхленный грунт поступает к фрезерному рабочему органу 4 и выбрасывается через окно. Дальность выброса

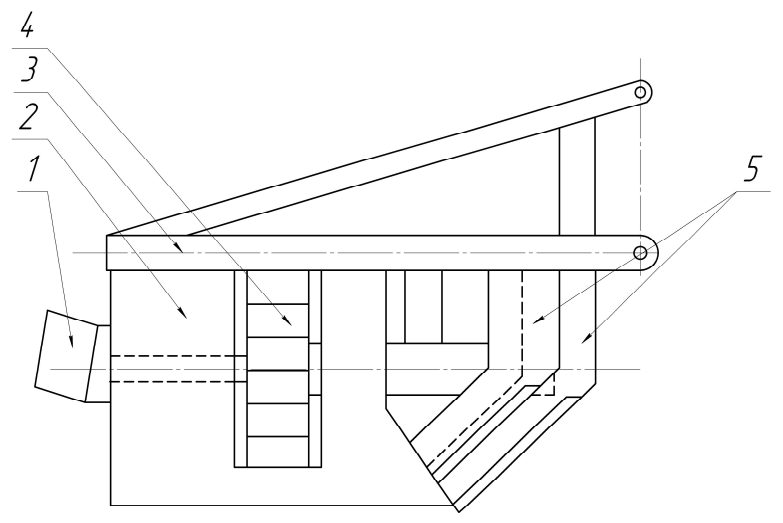

a

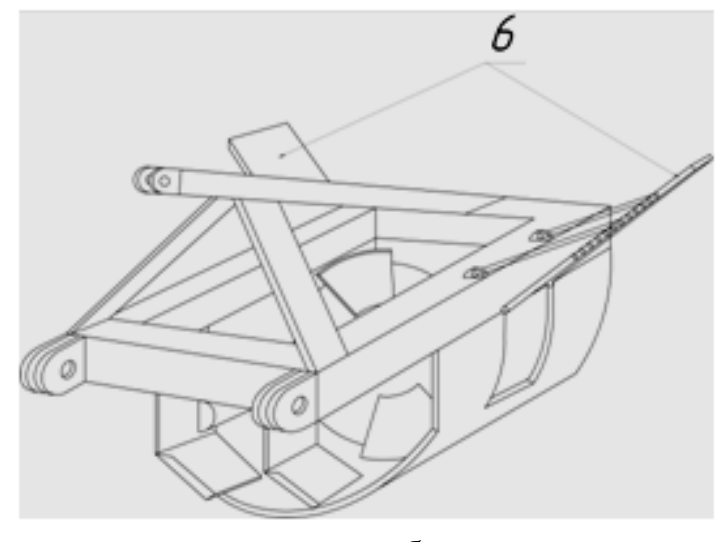

6

Рис. 5. Лесопожарная грунтометательная машина

грунта корректируется за счет изменения наклона пластины, направляющей грунт, 6 и за счет изменения частоты вращения фрезерного рабочего органа.

Защита фрезерного рабочего органа достигается за счет того, что он помещается внутрь кожухарыхлителя, который охватывает фрезерный рабочий орган снизу и предохраняет от ударов о корни и пни. Увеличение эффективности работы достигается за счет предварительного рыхления грунта кожухомрыхлителем и разрезания мелких корней тремя ножами, установленными непосредственно на кожухерыхлителе. Также ножи исключают попадание больших корней и пней к фрезерному рабочему органу за счет того, что, опираясь на них, лесопожарная грунтометательная машина способна наползать на препятствия, которые ножи не в состоянии перерезать.

Данная разработка имеет ряд преимуществ перед аналогами, и в данный момент создается промышленный образец для проведения полевых испытаний и дальнейшей оптимизации агрегата. 


\section{Библиографический список}

1. Лесные пожары и борьба с ними [Текст] : сб. науч. тр. / редкол. : Е. С. Арцыбашев (отв. ред) и др. ; ЛенНИИЛХ. - Л., 1989. - 145 с.

2. Лесная пирология [Текст] : учебное пособие / И. П. Ушатин ; М-во образования и науки РФ, ГОУ ВПО "ВГЛТА". - Воронеж, 2011. - 120 с.

3. Горешин, Н.М. Лесная пирология [Текст] / Н.М. Горешин, Н.А. Диченков, А.И. Швиденко. - Львов : Вища школа, Изд-во Львов. ун-та, 1981. - 160 с.

4. Калинин, Л.Б. Лесная пирология [Текст] / Л.Б. Калинин, В.Ф. Ковязин, С.В. Белов. - Спб. : ЛТА, 1993. - 80 с.

5. Зима, И.М. Механизация лесохозяйственных работ [Текст] : учеб. пособие / И.М. Зима, Т.Т. Малюгин. - 3-е изд., перераб. и доп. - М. : Лесн. пром-сть, 1976. - 416 с.

6. Кобяков, И.Д. Новые почвообрабатывающие машины [Текст] / И.Д. Кобяков // Земля сибирская, дальневосточная. - 1993. - № 1-2. - С. 19-22.

7. Метальников, М. С. Лесохозяйственные машины [Текст] / М.С. Метальников. - М. : Экология, 1991. - С. 6-10.

8. Гнусов, М.А. Обоснование параметров комбинированных рабочих органов грунтомета для прокладки минерализованных полос в лесу [Текст] : дис...канд. техн. наук / М.А. Гнусов. - Воронеж, 2014. - 140 с.

9. Федорченко, И.С. Экспериментальное устройство для метания грунта [Текст] / И.С. Федорченко, Е.И. Максимов // Лесной и химический комплексы: проблемы и решения: сб. ст. всерос. науч.-практ. конф. Красноярск, 2009. - Т.II. - С.234-239.

10. Бартенев, И.М. К вопросу о тушении лесных пожаров грунтом [Текст] / И.М. Бартенев, Д.Ю. Дручинин, М.А. Гнусов // Лесотехнический журнал. - 2012. - № 4 (8). - С. 97-101.

11. Пат. № 2496540 РФ, МПК А62 С 27/00. Пожарный грунтомет - полосопрокладыватель [Текст] / И.М. Бартенев, М.В. Драпалюк, М.А. Гнусов; заявитель и патентообладатель ФГБОУ ВПО «ВГЛТА». №2012126216/12., заявл. 22.06.12; опубл. 27.10.13, Бюл. № 30 .- 6 c.

12. Fridlei, R.B. A planting machine system for forest regeneration [Текст] / R.B. Fridlei, N.K. Yohuson // Transactions of the ASAE. - 1985. - Vol. 28. - No. 6. - P. 1770-1776.

13. Hakansson, I. A method for characterizing the state of compactness of the plow lever. [Текст] / I. Hakansson // Soil Tillage Research. - 1990. - no. 16. - pp. 18-21.

14. Reforestation with planting in northern Europe [Текст] / U. Nilsson, J. Luoranen, T. Kolstro, G. Orlander, P. Puttonen // Scandinavian Journal of Forest Research. - 2010. - No. 25(4). - P. 283-294.

\section{References}

1. Artsybashev E.S. [et al.] Lesnye pozhary i bor'ba s nimi [Forest fires and fight against them]. Leningrad, 1989, 145 p. (In Russian)

2. Ushatin I. P. Lesnaya pirologiya [Forest pyrology]. Voronezh, 2011, 120 p. (In Russian)

3. Goreshin N.M, Dichenkov N.A., Shvidenko A.I. Lesnaya pirologiya [Forest pyrology]. Lviv, 1981, 160 p. (In Russian)

4. Kalinin L.B, Kovyazin V.F, Belov S.V. Lesnaya pirologiya [Forest pyrology]. Saint-Petersburg, 1993,80 p. (In Russian)

5. Zima I.M., Malyugin T.T. Mekhanizatsiya lesokhozyaystvennykh rabot [Mechanization of silvicultural works]. Moscow, 1976, 416 p. (In Russian)

6. Kobyakov I.D. Novye pochvoobrabatyvayushchie mashiny [New soil-cultivating cars]. Zemlya sibirskaya, dal'nevostochnaya [Earth Siberian, Far East], 1993, no. 1-2, pp 19-22. (In Russian)

7. Metalnikov M.S. Lesokhozyaystvennye mashiny [Silvicultural cars]. Moscow, 1991, 6-10 p. (In Russian)

8. Gnusov M.A. Obosnovanie parametrov kombinirovannykh rabochikh organov gruntometa dlya prokladki mineralizovannykh polos $v$ lesu. Diss. kand. tekh. nauk [Justification of parameters of the combined working bodies of a gruntomet for laying of the mineralized strips in the wood PhD in Engineering Diss.]. Voronezh, 2014, 140 p. (In Russian) 
9. Fedorchenko I.S, Maximov E.I. Eksperimental'noe ustroystvo dlya metaniya grunta [The experimental device for a throwing of soil]. Lesnoy i khimicheskiy kompleksy: problemy i resheniya [Forest and chemical complexes: problems and decisions]. 2009, Vol. 2, pp. 234-239. (In Russian)

10. Bartenev I.M, Druchinin D.Yu, Gnusov M.A. K voprosu o tushenii lesnykh pozharov gruntom [On the issue of forest fire fighting soil]. Lesotekhnicheskii zhurnal, 2012, no. 4 (8), pp. 97-101. (In Russian)

11. Bartenev I.M, Drapalyuk M.V, Gnusov M.A. Pozharnyy gruntomet -polosoprokladyvatel' [The firefighter gruntomt - a polosoprokladyvatel]. Patent RF, no. 2496540, 2013.

12. Fridlei R.B., Yohuson N.K. A planting machine system for forest regeneration. Transactions of the ASAE. 1985, Vol. 28, no. 6, pp. 1770-1776.

13. Hakansson I. A method for characterizing the state of compactness of the plow lever. Soil Tillage Research. 1990, no. 16, pp. 18-21.

14. Nilsson U, Luoranen J, Kolstro T, Orlander G, Puttonen P. Reforestation with planting in northern Europe. Scandinavian Journal of Forest Research. 2010, no. 25(4), pp. 283-294.

\title{
Сведения об авторах
}

Ступников Дмитрий Сергеевич - аспирант кафедры механизации лесного хозяйства и проектирования машин ФГБОУ ВО «Воронежский государственный лесотехнический университет имени Г.Ф. Морозова», г. Воронеж, Российской Федерации; e-mail: Neiti1992@yandex.ru.

\section{Information about authors}

Stupnikov Dmitry Sergeevich - post-graduate student Department of Forestry Mechanization and Machine Design, Federal State Budget Education Institution of Higher Education «Voronezh State University of Forestry and Technologies named after G.F. Morozov», Voronezh, Russian Federation; e-mail: Neiti1992@yandex.ru.

DOI: $10.12737 / 19971$

УДК 630.383

\section{ИССЛЕДОВАНИЕ ЭКСПЛУАТАЦИОННЫХ СВОЙСТВ ДЕТАЛЕЙ ЛЕСНЫХ МАШИН В ЗАВИСИМОСТИ ОТ МЕТОДОВ УПРОЧНЕНИЯ ПОВЕРХНОСТНОГО СЛОЯ}

\author{
кандидат технических наук О. М. Тимохова ${ }^{1}$
}

доктор технических наук, профессор О. Н. Бурмистрова ${ }^{1}$

1 - ФГБОУ ВО «Ухтинский государственный технический университет», г. Ухта, Российская Федерация

Повышение работоспособности и долговечности деталей лесных машин в современном мире возможно различными способами. Химико-термическая и термическая обработки, газотермическое напыление, износостойкие наплавки позволяют повысить прочность и коррозионную стойкость деталей машин в несколько раз. Одним из перспективных направлений в области повышения коррозионной стойкости и долговечности деталей лесных машин является применение новых материалов и покрытий, таких как композиционные материалы, наноматериалы, металлокерамика. Возможности применения наноматериалов весьма разнообразны как в машиностроении, лесоинженерии, деревообработке, так и в лесной промышленности. В статье приведены результаты исследования комплексной упрочняющей обработки на износостойкость, коррозионную стойкость. Термореагирующий порошок ПТ-19Н-01 был объектом исследования материала, формирующего покрытие. В состав данного порошка были включены наночастицы целлюлозы. Для объективной оценки прочности связи между сформированными слоями покрытия с наночастицами отходов целлюлозного производства был использован штифтовой метод оценки прочности сцепления. Образцы, прошедшие термическую и химико-термическую обработку с последующим напылением, были подвергнугы проверке на адгезионную прочность. На основании экспериментальных данных были получены графики зависимости микротвёрдости от времени проведения исследования. Анализ графиков показал, что покрытие образцов (термообработка с напылением порошком, в со- 